\title{
Identification of Risk Factors Influencing Road Traffic Accidents
}

\author{
Mabrouk Touahmia \\ Department of Civil Engineering \\ College of Engineering, \\ University of Hail \\ Hail, Saudi Arabia \\ m.touahmia@uoh.edu.sa
}

\begin{abstract}
Road traffic accidents (RTAs) are becoming a major problem around the world, incurring enormous losses of human and economic resources. Recent reports from the World Health Organization (WHO) reveal that each year more than 1.25 million people are killed and 50 million are injured in road traffic accidents worldwide. In Saudi Arabia, statistics show that at least one traffic accident occurs every minute, causing up to $\mathbf{7 , 0 0 0}$ deaths and over 39,000 injuries annually. In this study, the main causes of RATs in the province of Hail are examined. The data was collected through the use of a survey which was developed to evaluate the effect of influencing parameters on RTA rate. The results show that $67 \%$ of RTAs result from human factors, $29 \%$ from road conditions and $4 \%$ from vehicle defects. Excessive speed and violation of traffic rules and regulations were found to be the main causes of RATs. Low rates of compliance with speed limit signs and seat-belt regulations were also observed. These findings highlight the need of strengthening effective traffic law enforcement alongside with improving traffic safety and raising public awareness.
\end{abstract}

Keywords-road traffic accidents; regulations; RTAs; survey; traffic; speeding

\section{INTRODUCTION}

Road traffic accidents (RTAs) are increasingly being recognized as one of the greatest public health issues, incurring heavy losses of human resources along with severe socioeconomic costs worldwide. Everyday, thousands of people are killed and injured on roads across the world. The World Health Organization (WHO) estimated that over 1.25 million deaths and 50 million injuries occur worldwide due to road crashes each year. Statistics anticipate RTAs to be the third among fifteen more often causes of death by 2020 [1]. Studies performed worldwide have shown that developing countries represent $67 \%$ of world RTA fatalities although they own only $11 \%$ of the vehicle fleet [2]. The increased rate of motor vehicle crashes worldwide has been attributed to the increased motorization of urban population. In Saudi Arabia, with its rapid expansion of road construction and increase in the number of vehicles, the rates of road accidents have increased dramatically. Over the past two decades, the Traffic Division of the Saudi Ministry of Interior has recorded more than 4 million road accidents $7 \%$ of which resulted in permanent disabilities [3]. An average of 19 deaths occurs daily in Saudi Arabia, which represents the country's principal cause of death in adult males, aged 16 to 36, giving a rate of 23.3 traffic accident fatalities per 100,000 population [3-4]. The economic losses due to RTAs in Saudi Arabia were estimated to exceed 6 billion US dollars annually, in addition to other health and social impacts due to injuries [5]. Despite the fact that Saudi Arabia has a high rate of traffic accidents, relatively little literature about this problem has been produced. Previous studies observed that Saudi Arabia has a higher rate of RATs occurrence than other developing countries with comparable vehicle ownership levels [6-7]. Excessive speed and violation of traffic laws and regulations were found to be the main causes of RTAs in Saudi Arabia [8-12].

The causes of RATs are complex and involve the interaction of a combination of factors that include road users, the vehicle, roadway, environment and the way they interact [13-14]. Acquiring knowledge of the risk factors that contribute to road traffic crashes is important in formulating the priorities of action plans and interventions that can reduce the risks associated with those factors. It is generally recognised that a multi-disciplinary approach is essentially needed in understanding the main causations of RATs and providing better and appropriate solutions. The aim of this research is to identify the contributing factors affecting road traffic accidents in the province of Hail, Saudi Arabia. It is expected that the findings of the study will contribute to raising public awareness and designing policies for road safety planning in the Kingdom of Saudi Arabia and other similar countries.

\section{SURVEY DEVELOPMENT}

To meet the objectives of this study a structured and comprehensive survey was developed based on an extensive literature to collect the necessary data for analysis. The methodology employed was based on both qualitative and quantitative methodologies. The questionnaire contains 39 items of different types such as, Likert-scale type, multiple answers, single answer, and open questions and includes detailed information on the survey participants, their driving behavior and practices, their knowledge and awareness of 
traffic laws and regulations, their assessment of road conditions and the interactions between these factors. The survey was designed to allow the researchers to identify the most profound difficulties and traffic safety problems that road users face. It is also designed to serve the researchers to identify the level of adherence and understanding of traffic regulations of the individual being interviewed. In addition, the questionnaire was designed to allow the researchers to provide measures of the traffic experience, knowledge, perception, attitude, traffic safety and road conditions.

The data was collected through the questionnaire which is composed of four main sections namely: the first section includes general information about the participants, the second section evaluates the driving attitudes and practices of participants, the third section assesses knowledge and awareness of participants about traffic laws and regulations, and the fourth section assesses traffic safety rules awareness of the participants. The survey allows identifying the most thoughtful difficulties and trafficking safety problems that road users face in Hail. It also provides an evaluation of the traffic experience, awareness, attitude, traffic safety and road conditions and allows identifying the level of understanding and compliance with traffic regulations of the participants.

\section{DATA PROCESSING}

More than 500 questionnaires were distributed randomly to a sample of people living in Hail. The total number of completed and returned questionnaires was 208 giving a rate of $41.6 \%$. The collected data was analyzed by the statistical package SPSS, which was extensively used to produce different statistical tables of varying kinds, and in simple statistical computations. A discussion is provided on the importance of data considerations, particularly with respect to discrepancies existing in accident-casualty data from different sources.

\section{RESULTS AND DISCUSSION}

The results of the survey show that the respondents are mainly students falling within the age group of 19 to 29 years as illustrated in Figure 1. When asked about the insurance, $60 \%$ of the respondents answered having insurance, either full or third party coverage, while $40 \%$ of them mentioned not having an insurance as shown in Figure 2. As far as the driving license is concerned, $76 \%$ of the survey respondents mentioned possessing a driving license, while a relatively high percentage of them $(24 \%)$ reported not having driving license as shown in Figure 3. The durations of the survey participants driving licenses are shown in Figure 4. It is worth noting that $94 \%$ of the unlicensed respondents are high school students, aged less than 18 years old who drive on a daily basis. This result highlights the need for a strict driving license policy to enhance current measures against unlicensed driving, particularly in the area of enforcement practices. Unlicensed drivers represent a serious danger within the drivers' community due to the fact they have not undergone appropriate training and testing and may, therefore, be deficient in some aspects of the knowledge, awareness and skills required to drive safely. Furthermore, drivers who are unauthorized may have less incentive to comply with road traffic regulations and laws. Driving without a valid license remains a serious problem in many countries despite ongoing improvement in traffic law enforcement practices. A survey in the USA has shown that approximately $20 \%$ of fatal crashes involves at least one driver who does not possess a valid license at the time of the crash [15-16]. In 2000, it was estimated that there were around 7,000 crashes $(11,000$ casualties) in UK involving drivers subsequently prosecuted for unlicensed driving [17]. In Australia, unlicensed drivers represent over $5 \%$ of the drivers involved in fatal crashes [18].

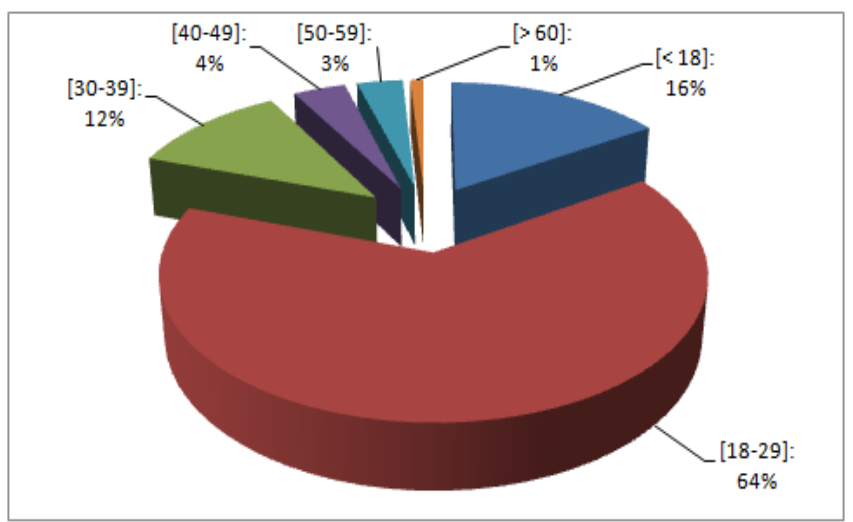

Fig. 1. Age breackdown of the respondents.

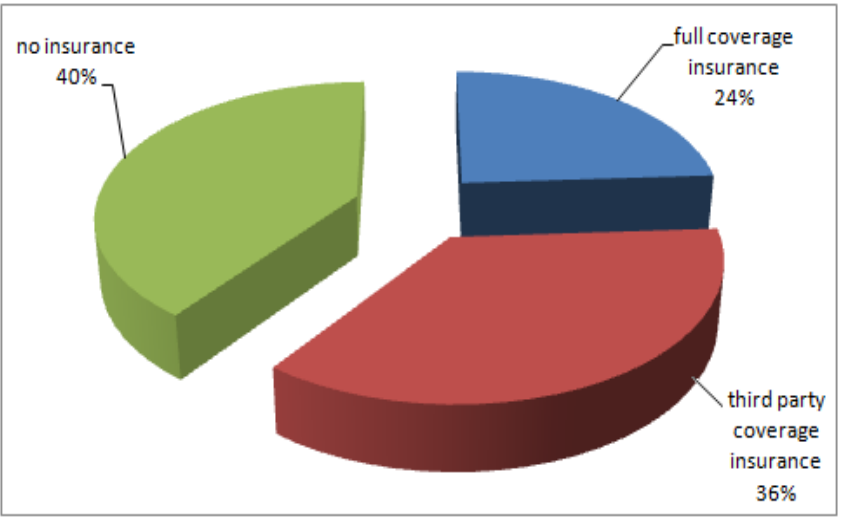

Fig. 2. Rate of insurance coverage of the participants.

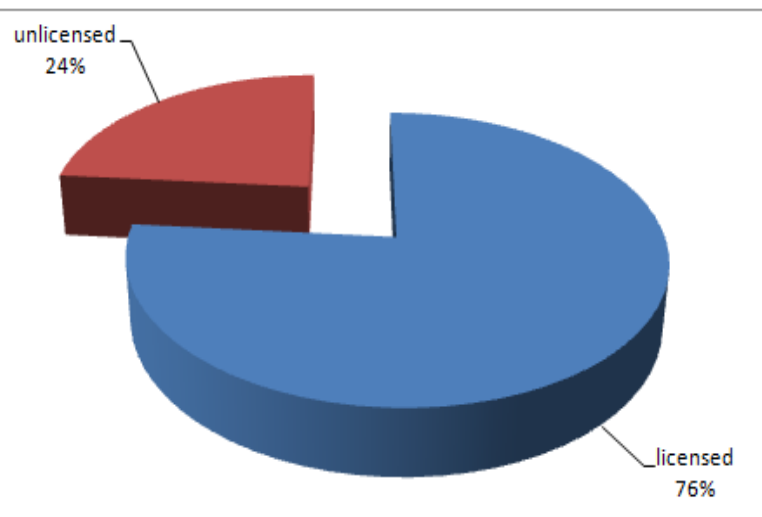

Fig. 3. Rate of licensed-unlicensed driving. 
When asked about their knowledge about traffic laws and regulations, approximately $23 \%$ of the participants reported having very good/good levels, $65 \%$ mentioned they have moderate level and $14 \%$ indicate having weak/very weak knowledge about traffic regulations. Figure 5 illustrates the participants' levels of knowledge on traffic regulations. Similar studies were reported by other researchers [19-20]. This result emphasizes the need for more training and education campaigns concerning the importance and benefits of traffic laws and regulations.

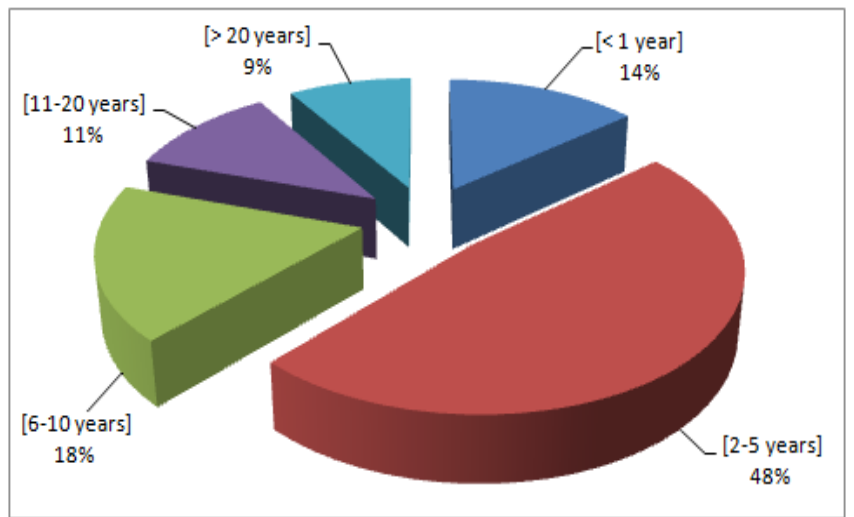

Fig. 4. Durations of the respondents' driving licenses.

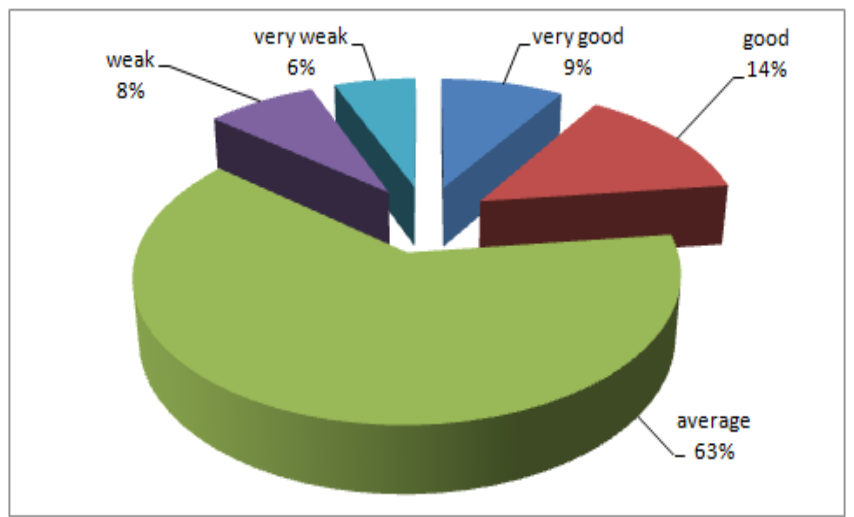

Fig. 5. Respondents knowledge of traffic regulations.

A further analysis of the questionnaire data showed that $63 \%$ of the participants experienced RATs at least once in the past as shown in Figure 6. Human factors are the leading contributing factor in any RATs study including this one. Data indicated that $67 \%$ of the accidents resulted from human errors, $29 \%$ from road defects and 4\% from vehicle conditions as illustrated in Figure 7. Approximately two thirds of the respondents reported not complying with the speed limit signs and they often drive faster than the speed limits in urban roads and highways as shown in Figure 8. This result reflects the lack of awareness among a large number of respondents concerning the danger and consequences of non-compliance with speed limit regulations. The survey data indicate that excessive speeding is the main cause of road crashes among the human causes of accidents.

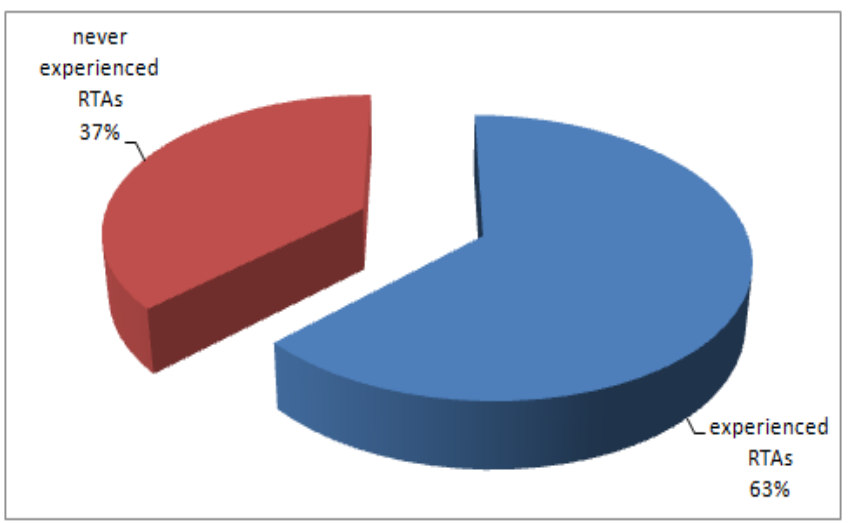

Fig. 6. Rate of involvement in RATs.

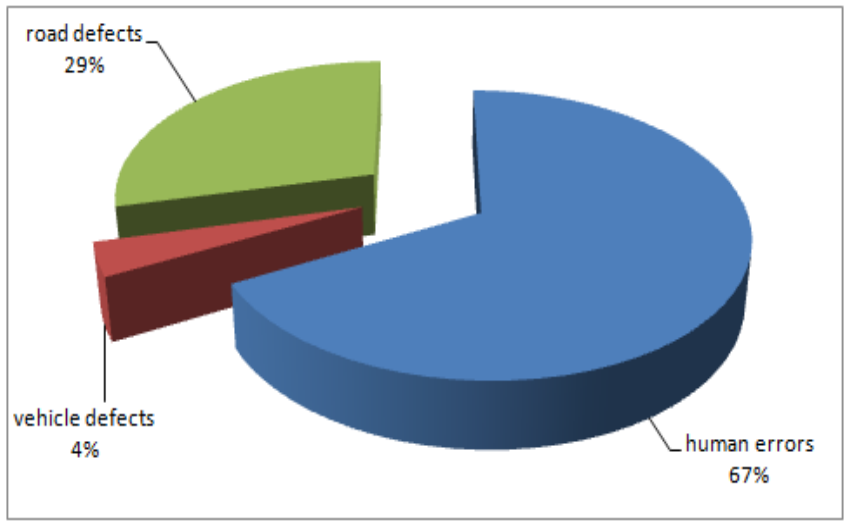

Fig. 7. Main causes of RATs

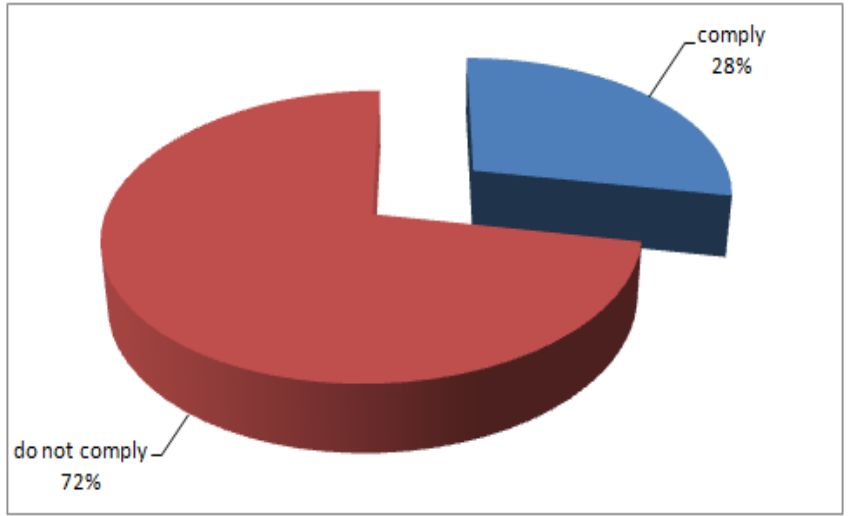

Fig. 8. Rate of compliance with speed limit regulations.

This result is consistent with previous studies [3,4, 7-9] which pointed out that the majority of traffic accidents in Saudi Arabia are directly related to human characteristics and errors, while road safety and vehicle's condition contributed to only $20 \%$ of the accidents. It is worth noting that approximately one third of the accidents are caused by road conditions as reported by the participants. Although there are many variables that can lead to RATs, roadway's conditions like pavement quality, shoulders, visibility, signals, lane marking, traffic control 
devices and intersections, can be considered as major potential factors in reducing RATs.

Data from the safety section of the survey show that only $34 \%$ of the respondents comply with seat-belts use whilst driving as shown in Figure 9. A further examination of the respondents' reasons for not using seat-belts while driving showed that $54 \%$ claims not doing so due to discomfort, $16 \%$ to forgetfulness, $14 \%$ to carelessness and $6 \%$ to uselessness. However, when asked about the importance of wearing a seatbelt, $96 \%$ of the respondents mentioned they are convinced of its significance in saving lives and reducing severity of road crash injuries. This result emphasizes the need for more public awareness campaigns as well as effective laws enforcement to raise divers' compliance with seat-belts use.

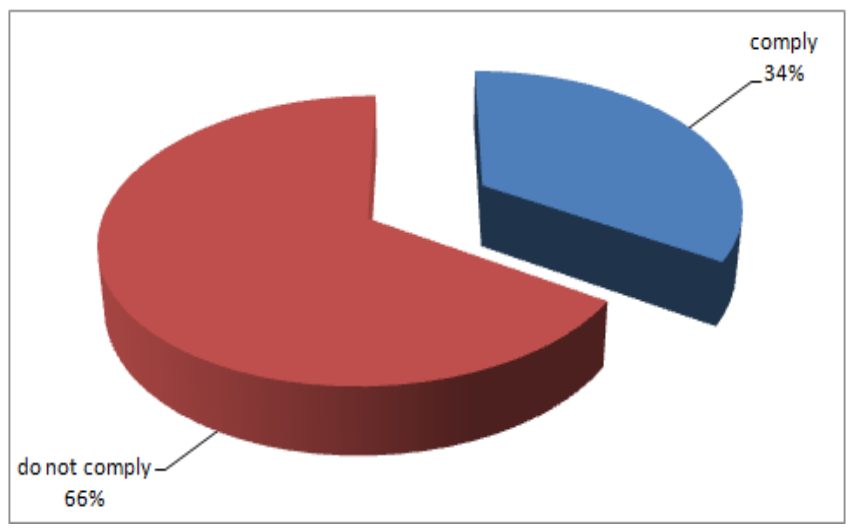

Fig. 9. Rate of compliance with seat-belt regulations.

\section{CONCLUSION}

RATs are a leading cause of death and injury in Saudi Arabia, resulting in significant social and economic costs. In this study, the main causes of RATs in the province of Hail are analyzed. The data was collected through the use of a survey which was developed based on literature. The surveyquestionnaire consisted of four sections, namely, participants' general information, driving attitude and practice, traffic regulation knowledge and traffic safety awareness. The results show that $63 \%$ of the participants experienced road crashes at least once in the past, where $67 \%$ of these accidents are caused by human errors, $29 \%$ by road conditions and $4 \%$ by vehicle defects. Data analysis indicates that excessive speeding is the main cause of road crashes. Although most of the participants reported having a good to moderate knowledge and understanding of road traffic laws and regulations, low rates of compliance with speed limit signs and seat-belts use were observed. In general, it can be concluded that further efforts should be undertaken for setting and enforcing effective traffic laws and road safety legislations alongside with promoting public awareness on traffic safety. The issue of improving the quality of roads and all related traffic safety equipments is also a critical factor of reducing RATs.

\section{ACKNOWLEDGMENT}

This research was funded by the Deanship of Scientific Research at the University of Hail, Saudi Arabia, under contract E012-CE. The author would like to extend his gratitude to the Deanship of Scientific Research and to the College of Engineering at the University of Hail for providing all facilitations required for this research.

\section{REFERENCES}

[1] World Health Organization, Global Status Report on Road Safety 2015, 2015

[2] A. A. Galal, "Traffic accidents and road safety management: A comparative analysis and evaluation in industrial, developing and richdeveloping countries", 29th Southern African Transport Conference, pp. 530-540, 2010

[3] F. A. Mansuri, A. H. Al-Zalabani, M. M. Zalat, R. I. Qabshawi, "Road safety and road traffic accidents in Saudi Arabia: A systematic review of existing evidence", Saudi Medical Journal, Vol. 36, No. 4, pp. 418-424, 2015

[4] E. S. Gharaibeh, A. M. Abu Abdo, "Assessment of Traffic Safety and Awareness among Youth in Al-Ahsa Region, Saudi Arabia", Journal of Emerging Trends in Engineering and Applied Sciences, Vol. 2, No. 2, pp. $210-215,2011$

[5] A. J. Al-Saif, Prediction of Traffic Accidents in GCC, Solutions, and the Role of Al-Shura Council in Addressing That, Saudi Arabia as a Model, King Fahd National Library, 2010

[6] A. Bener, F. M. Abu-Zidan, A. K. Bensiali, A. A. K. Al-Mulla, K. S. Jadaan, "Strategy to improve road safety in developing countries", Saudi Medical Journal, Vol. 24, No. 6, pp. 603-608, 2003

[7] S. F. Ansari, A. M. Mandoorah, K. Moutaery, "Causes and Effects of Road Traffic Accidents in Saudi Arabia”, Public Health, Vol. 114, No. 1, pp. 37-39, 2000

[8] S. Ramisetty-Mikler, A. Almakadma, "Attitudes and behaviors towards risky driving among adolescents in Saudi Arabia", International Journal of Pediatrics and Adolescent Medicine, Vol. 3, No. 2, pp. 55-63, 2016

[9] Y. A. Al-Turki, "How can Saudi Arabia use the decade of action for road safety to catalyse road traffic injury prevention policy and interventions?", International Journal of Injury Control and Safety Promotion, Vol. 21, No. 4, pp. 397-402, 2013

[10] T. Usman, L. Fu, F. Miranda-Moreno, "Quantifying safety benefit of winter road maintenance: Accident frequency modelling", Accident Analysis \& Prevention, Vol. 42, No. 6 pp. 1878-1887, 2010

[11] A. S. Al-Ghamdi, "Analysis of Traffic Accidents at Urban Intersections in Riyadh", Accident Analysis \& Prevention, Vol. 35, No. 5, pp. 717724, 2003

[12] J. T. Wong, Y. S. Chung, "Investigating Driving Styles and Their Connections to Speeding and accident Experience", Journal of the Eastern Asia Society for Transportation Studies, Vol. 8, pp. 1944-1958, 2010

[13] M. H. Khan, I. Ahmed, N. Zia, T. S. Babar, T. S. and K. S. Babar, "Road traffic accidents: Study of risk factors", Professional Medicine Journal, Vol. 14, No. 2, pp. 323-327, 2007

[14] D. Eisenberg, "The mixed effects of precipitation on traffic crashes", Accident Analysis and Prevention", Vol. 36, No. 4, pp. 637-647, 2004

[15] R. A. Scopotz, C. E. Hatch, B. H. Delucia, K.A. Tays, "Unlicensed to kill”, AAA, Foundation for Traffic Safety, 2003

[16] C. L. Hanna, D. M. Taylor, M. A. Sheppard, L. Laflamme, "Fatal crashes involving young unlicensed drivers in the U.S", Journal of Safety Research, Vol. 37, No. 4, 385-393, 2005

[17] UK Department of Transport Research, Unlicensed Driving, Report No. 4, 2003

[18] B. Watson, "A survey of unlicensed driving offenders", Road Safety Research, Policing \& Education Conference, pp. 181-190, 2004 
[19] R. A. Al-Naggar, K. Al-Jashamy, "Knowledge, Attitude and Practice towards Road Traffic Regulations Among University Students, Malaysia", International Medical Journal Malaysia, Vol. 9, No. 2, pp: 29-34, 2010

[20] Y. M. Al-Khaldi, "Attitude and practice towards road traffic regulations among students of health Sciences College in Aseer region", Journal of Family \& Community Medicine, Vol. 13, No. 3, pp.109-13, 2006 